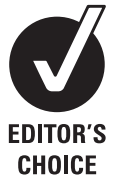

- Additional data are published online only. To view these files please visit the journal online (http://oem.bmj.com/).

${ }^{1}$ Hollis Laboratory, Division of Environmental and Occupational Health Sciences, National Jewish Health, Denver, Colorado, USA

${ }^{2}$ Department of Environmental and Radiological Health Sciences, Colorado State University, Fort Collins, Colorado, USA

${ }^{3}$ University of Colorado Denver School of Medicine and Colorado School of Public Health, Denver, Colorado, USA

${ }^{4}$ Oak Ridge Associated Universities, Oak Ridge, Tennessee, USA

\section{Correspondence to}

Dr Michael V Van Dyke, Division of Environmental and

Occupational Health Sciences, National Jewish Health, 1400 Jackson St, Denver, C0 80206, USA; vandykem@njhealth.org

This work is from a dissertation submitted to the Academic Faculty of Colorado State University in partial fulfilment of the requirements for the degree of Doctor of Philosophy.

Accepted 9 March 2011

Published Online First

2 April 2011

\title{
Exposure and genetics increase risk of beryllium sensitisation and chronic beryllium disease in the nuclear weapons industry
}

\author{
Michael V Van Dyke, ${ }^{1,2}$ John W Martyny, ${ }^{1,2,3}$ Margaret M Mroz, ${ }^{1}$ Lori J Silveira, \\ Matt Strand, ${ }^{1}$ Donna L Cragle, ${ }^{4}$ William G Tankersley, ${ }^{4}$ Susan M Wells, ${ }^{4}$ \\ Lee $S$ Newman, ${ }^{3}$ Lisa A Maier ${ }^{1,3}$
}

\section{ABSTRACT}

Objectives Beryllium sensitisation (BeS) and chronic beryllium disease (CBD) are caused by exposure to beryllium with susceptibility affected by at least one well-studied genetic host factor, a glutamic acid residue at position 69 (E69) of the HLA-DP $\beta$ chain (DP $\beta E 69)$. However, the nature of the relationship between exposure and carriage of the DPßE69 genotype has not been well studied. The goal of this study was to determine the relationship between DP $\beta E 69$ and exposure in BeS and CBD.

Methods Current and former workers $(n=181)$ from a US nuclear weapons production facility, the Y-12 National Security Complex (Oak Ridge, Tennessee, USA), were enrolled in a case-control study including 35 individuals with BeS and 19 with CBD. HLA-DPB1 genotypes were determined by PCR-SSP. Beryllium exposures were assessed through worker interviews and industrial hygiene assessment of work tasks.

Results After removing the confounding effect of potential beryllium exposure at another facility, multivariate models showed a sixfold (OR 6.06, 95\% Cl 1.96 to 18.7) increased odds for BeS and CBD combined among DP $\beta$ E69 carriers and a fourfold (OR 3.98, 95\% Cl 1.43 to 11.0) increased odds for those exposed over an assigned lifetime-weighted average exposure of $0.1 \mu \mathrm{g} /$ $\mathrm{m}^{3}$. Those with both risk factors had higher increased odds (OR 24.1, 95\% Cl 4.77 to 122).

Conclusion DP $\beta E 69$ carriage and high exposure to beryllium appear to contribute individually to the development of BeS and CBD. Among workers at a beryllium-using facility, the magnitude of risk associated with either elevated beryllium exposure or carriage of DPßE69 alone appears to be similar.

\section{INTRODUCTION}

Beryllium is a low-density metal used in the automotive, electronics, communications, medical, defence, nuclear and aerospace industries. Workers involved in the fabrication or production of beryllium-containing materials are at risk for developing beryllium sensitisation (BeS) and chronic beryllium disease (CBD). The risk of BeS and $\mathrm{CBD}$ varies by workplace and likely by exposure level. Prevalences of up to $15 \%$ for BeS and $8 \%$ for $\mathrm{CBD}$ have been reported in crosssectional studies of beryllium-exposed workforces. ${ }^{12}$

\section{What this paper adds}

- Beryllium sensitisation and chronic beryllium disease (CBD) are caused by exposure to beryllium with susceptibility affected by at least one genetic host factor, a glutamic acid residue at position 69 (E69) of the HLA-DP $\beta$ chain (DP $\beta E 69)$.

- Previous studies evaluating the relationship between beryllium exposure and carriage of the DP $\beta E 69$ genotype have been limited by small numbers of CBD cases or non-significant beryllium exposure effects.

- Among workers at a beryllium-using facility, DP 3 E69 carriage and high exposure to beryllium appear to be risk factors that contribute individually to the development of beryllium sensitisation and CBD, with a similar magnitude of increased risk associated with either elevated beryllium exposure or carriage of DP $\beta E 69$ alone.

- This study supports the need for primary prevention through exposure reduction in the workplace aimed at the more susceptible population, those with the DP $\beta E 69$ genetic variant.

However, the exposure-response relationship does not appear to be linear as case reports and epidemiology studies have documented cases of BeS and CBD among individuals with low

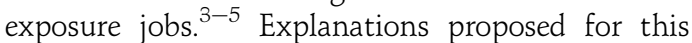
lack of a linear exposure-response relationship have included different physical or chemical forms of beryllium, ${ }^{6}$ exposure to smaller particle sizes ${ }^{7-10}$ and dermal exposure. ${ }^{11-13}$

Host factors also appear to influence the effects of beryllium exposure on the risk of $\mathrm{BeS}$ and $\mathrm{CBD}$. Richeldi et al $^{14}$ demonstrated over-representation of HLA-DPB1 alleles with a glutamic acid at position 69 of the $\beta$ chain (DP $3 E 69)$ in $\mathrm{CBD}$ cases $(97 \%$, $\mathrm{n}=33)$ compared to controls $(30 \%, \mathrm{n}=44)$. The results of this study have since been verified, showing significantly higher proportions of DP $3 E 69$-containing alleles in cases of both CBD (73-97\%) and $\mathrm{BeS}(68-90 \%)$ as compared to controls $(30-47 \%) .{ }^{15-22}$ Only two studies have 
evaluated the combined effect of exposure and genetics on the risk of $\mathrm{CBD}$. The first study, which was limited by only six cases of $\mathrm{CBD}$, identified increased risks for $\mathrm{CBD}$ from both higher exposure (OR 10.1, 95\% CI 1.1 to 93.7) and carriage of DPßE69 (OR 11.8, 95\% CI 1.3 to 108.8). ${ }^{15}$ The second study, with 65 $\mathrm{CBD}$ cases, identified increased risk for carriage of DP $\beta E 69$ (OR 19.1, 95\% CI 7.10 to 55.92 ) but was unable to demonstrate significant exposure effects. ${ }^{22}$

The overall goal of this study was to evaluate the individual contributions of exposure and genetic factors to the risk of BeS and CBD in a larger group of workers. To accomplish this goal, we conducted a case-control study of workers in a nuclear weapons production facility. The aims of the study were: (1) to describe the exposure risk factors for $\mathrm{BeS}$ and $\mathrm{CBD}$ among a newly enrolled group of nuclear weapons workers; (2) to verify carriage of DP $3 E 69$ as a risk factor for BeS and CBD; and (3) to define the interaction of DP $\beta E 69$ and beryllium exposure level on the risk of developing BeS and CBD.

\section{METHODS \\ Worksite description}

The current investigation was undertaken at an active nuclear weapons production facility in Oak Ridge, Tennessee, at the Y-12 National Security Complex where beryllium compounds have been heated, pressed, shaped, moulded and machined since the early 1950s. In addition to Y-12, there are two other longterm US Department of Energy facilities in Oak Ridge, with limited beryllium operations, the East Tennessee Technology Park (ETTP, formerly the K-25 Gaseous Diffusion Plant) and Oak Ridge National Laboratory (X-10). These additional facilities are mentioned since some of the participants in this study also worked at these other facilities. A more detailed description is provided in the online data supplement.

\section{Study recruitment and design}

All workers who had ever worked at Y-12 and had ever undergone beryllium medical surveillance through current or former worker medical screening programs were eligible to participate in this study. Workers were recruited using mailings, newspaper articles and locally publicised study presentations. BeS cases were required to have two or more abnormal blood beryllium lymphocyte proliferation test (BeLPT) results, and included both those who had undergone a medical evaluation to rule out CBD and those who had not been medically evaluated. CBD cases were required to have evidence of $\mathrm{BeS}$ along with either: (1) granulomas on biopsy; or (2) both an abnormal bronchoalveolar lavage (BAL) BeLPT and $>15 \%$ lymphocytes in BAL fluid. Controls were current or former Y-12 workers with at least two normal (one within the last 5 years) and no abnormal BeLPTs. Controls were frequency matched approximately $2: 1$ to cases based on sex, race, work status (current versus former) and decade of hire at Y-12. The study protocol was reviewed and approved by the National Jewish Health Institutional Review Board and the US Department of Energy Central Beryllium Institutional Review Board. All participants were required to sign informed consent documents.

\section{DNA extraction and HLA-DPB1 genotyping}

Genomic DNA was extracted from peripheral blood and DNA was extracted using the Paxgene Blood DNA kit (OIAGEN, Valencia, California, USA). Genotyping was performed using polymerase chain reaction-sequence specific primer (PCR-SSP) analysis of HLA-DPB1 and coding sequence polymorphisms based on the methods of Welsh and Bunce. ${ }^{23}$ More detailed information on genotyping methods is provided in the online data supplement. For this study, participants were coded as carriers of one, two or no copies of DP $\beta E 69$.

\section{Exposure assessment}

Exposure interviews were conducted with all participants using a structured exposure questionnaire. Interviews were conducted by four interviewers with experience in exposure assessment projects and a valid security clearance. Participants were asked to verify the start and end dates for job assignments and to estimate the average work hours per week. Participants were also asked about their specific tasks (turning, grinding, plating, cleaning, etc) and to classify each task in an exposure category that referred to whether they worked directly with berylliumcontaining materials or only in proximity to beryllium operations. For each of the tasks, the participant provided a percentage of time spent performing the task and a percentage of time spent performing the task with beryllium. These questionnaires were used directly to determine whether a worker ever worked in a specific job classification, the worker's highest reported exposure category, the number of years a participant directly worked with beryllium and the year of first beryllium exposure. The questionnaires were also used to identify unique combinations of exposure category and task. For each of these combinations, related industrial hygiene exposure measurements were selected from data obtained from Y-12 and other beryllium fabrication facilities with similar processes. An arithmetic mean of the selected exposure measurements was calculated for each combination. These task or process exposures were used to calculate an assigned cumulative exposure for each participant by summing the job-specific exposures for each time period obtained by multiplying the task exposure estimate by the percentage of time working with beryllium in that time period, the percentage of time performing the task, the number of years spent in the job and the ratio of the average number of work hours per week to $40 \mathrm{~h}$. An assigned lifetime-weighted average exposure was calculated by dividing the assigned cumulative exposure by the total number of work years. More details on the exposure assessment methods are included in the online data supplement.

\section{Statistical analysis}

We used SAS v 9.1 for statistical analyses. Univariate analyses of categorical variables were performed using Fisher's exact tests. Continuous variables were compared using Wilcoxon rank sum (two samples) and Kruskal-Wallis (more than two samples) tests. Unconditional logistic regression was used for multivariate models, and the combined $\mathrm{BeS} / \mathrm{CBD}$ outcome $(1=\mathrm{BeS}$ or $\mathrm{CBD}$, $0=$ control) was used to increase power. Candidate variables in multivariate models included one genetic variable specifying DP $\beta E 69$ status (carriage of 0 vs 1 or 2 copies of DP $\beta E 69$ ), at least one exposure variable, other demographic variables with univariate $p$ values $<0.25$, and first-order interactions. Continuous exposure variables were tested individually both as a continuous covariate, and as binary variables based on a median split or assigned lifetime-weighted average exposures at proposed occupational exposure limits of $0.05 \mu \mathrm{g} / \mathrm{m}^{3}, 0.1 \mu \mathrm{g} / \mathrm{m}^{3}$ and $0.2 \mu \mathrm{g} / \mathrm{m}^{3}$. Stepwise model building methods specified a 0.1 significance level to enter the model and a 0.05 significance level for a variable to remain in the model. Two-way interactions with significance levels at or below 0.1 were included in the final model. 


\section{RESULTS}

\section{Study population}

A total of 191 participants enrolled in this study. Of these, we excluded three subjects with an inadequate blood sample, three subjects who had only one abnormal BeLPT that was not confirmed to be abnormal with a second BeLPT, two subjects who had a concomitant diagnosis of sarcoidosis with normal BeLPTs and no diagnosis of CBD or BeS, and two subjects who had difficulty recalling their work tasks. This left a total of 181 participants including 127 controls, 19 cases of CBD and 35 cases of BeS as shown in table 1. Included in the 35 cases of BeS are 15 individuals each with at least two abnormal BeLPTs who had not undergone a full medical evaluation to rule out CBD.

\section{Demographic characteristics}

As shown in table 1, the median age for study participants was 62 . While cases of CBD were typically younger (58) compared to controls (63), the difference was not statistically significant. Of the 181 participants, only 17 (9\%) were female, consistent with the traditionally male-dominated workforce at Y-12. In terms of race, there was a significantly greater proportion of AfricanAmericans with CBD (16\%) as compared to controls $(2 \%$, $p=0.029$ ). This may reflect our difficulty in recruiting AfricanAmerican controls. Approximately $57 \%$ of the participants had ever been smokers with about $7 \%$ classifying themselves as current smokers. There were no differences in smoking status by disease classification. The median year of hire at Y-12 was 1970 (range, 1947-2001). The median number of years participants had worked at Y-12 was 25 (range, <1-47). BeS cases worked significantly fewer years at Y-12 (20 years) compared to controls ( 25 years, $\mathrm{p}=0.024)$. Among those classified as BeS, there were no significant differences in terms of smoking status, age or number of years worked at Y-12 between participants who had clinically confirmed $\mathrm{BeS}$ and those who had not undergone clinical evaluation to rule out $\mathrm{CBD}$.

\section{Exposure characteristics}

As shown in table 2, the median number of years directly exposed to beryllium was slightly higher for CBD cases (2.3 years) compared to controls (1.3 years, $\mathrm{p}=0.120$ ), and significantly higher compared to BeS cases ( 0.48 years, $\mathrm{p}=0.010)$. CBD cases also tended to have higher median assigned cumulative exposures $\left(2.64 \mu \mathrm{g} / \mathrm{m}^{3}\right.$-years $)$ and assigned lifetime-weighted average exposures $\left(0.11 \mu \mathrm{g} / \mathrm{m}^{3}\right)$ as compared to controls $\left(0.98 \mu \mathrm{g} / \mathrm{m}^{3}\right.$-years, $\mathrm{p}=0.062$ and $0.03 \mu \mathrm{g} / \mathrm{m}^{3}$, $p=0.032$, respectively) and BeS cases $\left(0.26 \mu \mathrm{g} / \mathrm{m}^{3}\right.$-years, $\mathrm{p}=0.022$ and $0.02 \mu \mathrm{g} / \mathrm{m}^{3}, \mathrm{p}=0.031$, respectively). In fact, CBD cases had significantly higher exposures in terms of years handling beryllium, assigned cumulative beryllium exposure, assigned lifetimeweighted average beryllium exposure and highest task exposure as compared to BeS cases. In addition, controls tended to have higher median assigned cumulative exposure $\left(0.98 \mu \mathrm{g} / \mathrm{m}^{3}\right.$-years $)$ and highest task exposure $\left(1.00 \mu \mathrm{g} / \mathrm{m}^{3}\right)$ as compared to BeS cases $\left(0.26 \mu \mathrm{g} / \mathrm{m}^{3}\right.$-years, $\mathrm{p}=0.096$ and $0.26 \mu \mathrm{g} / \mathrm{m}^{3}, \mathrm{p}=0.005$, respectively). Details of additional exposure characteristics are presented in the online data supplement.

Because we did not fully evaluate exposures at the K-25 facility, we assessed exposure measures excluding those cases and controls who had worked at the K-25 facility as shown in table 2. When those who had ever worked at K-25 were excluded, both median assigned cumulative and median assigned lifetime-weighted average exposures were significantly higher ( $p=0.011$ and $p=0.001$, respectively) for CBD cases $\left(3.86 \mu \mathrm{g} / \mathrm{m}^{3}\right.$ years, $\left.0.13 \mu \mathrm{g} / \mathrm{m}^{3}\right)$ compared to controls $\left(1.02 \mu \mathrm{g} / \mathrm{m}^{3}\right.$-years, $0.03 \mu \mathrm{g} / \mathrm{m}^{3}$ ) but not for BeS cases compared to either CBD cases or controls $\left(2.43 \mu \mathrm{g} / \mathrm{m}^{3}\right.$-years, $\left.0.10 \mu \mathrm{g} / \mathrm{m}^{3}\right)$ not having worked at $\mathrm{K}-25$.

\section{Genotype characteristics}

HLA-DPB1 alleles were in Hardy-Weinberg equilibrium for controls $(p=0.73)$ and BeS cases $(p=0.21)$ but not CBD cases $(p=0.0051)$ when considering all alleles. Failure to meet HardyWeinberg criteria is not unexpected for cases when a disease

Table 1 Demographic characteristics of study participants

\begin{tabular}{|c|c|c|c|c|}
\hline Characteristic & Total $(n=181)$ & Controls $(n=127)$ & $\operatorname{BeS}^{*}(n=35)$ & $\operatorname{CBD}(n=19)$ \\
\hline \multicolumn{5}{|l|}{ Gender, n (\%) } \\
\hline Male & $164(91 \%)$ & $116(91 \%)$ & $31(89 \%)$ & $17(89 \%)$ \\
\hline Female & 17 (9\%) & $11(9 \%)$ & $4(11 \%)$ & 2 (11\%) \\
\hline \multicolumn{5}{|l|}{ Race, n (\%) } \\
\hline White & $174(96 \%)$ & $124(98 \%)$ & $34(97 \%)$ & $16(84 \%)$ \\
\hline African-American & $7(4 \%)$ & $3(2 \%)$ & $1(3 \%)$ & $3(16 \%) \dagger$ \\
\hline \multicolumn{5}{|l|}{ Smoking status, n (\%) } \\
\hline Never & $78(43 \%)$ & $57(45 \%)$ & $13(37 \%)$ & $8(42 \%)$ \\
\hline Former & $91(50 \%)$ & $61(48 \%)$ & $19(54 \%)$ & $11(58 \%)$ \\
\hline Current & $12(7 \%)$ & $9(7 \%)$ & $3(9 \%)$ & $0(0 \%)$ \\
\hline \multicolumn{5}{|l|}{ Work status, n (\%) } \\
\hline Current worker & $85(47 \%)$ & $58(46 \%)$ & $15(43 \%)$ & $12(63 \%)$ \\
\hline Former worker & $96(53 \%)$ & $69(54 \%)$ & $20(57 \%)$ & $7(37 \%)$ \\
\hline Median age (range) & $62(30-87)$ & $63(30-87)$ & $62(41-87)$ & $58(48-81)$ \\
\hline Median year of hire (range) & 1970 (1947-2001) & $1969(1947-2001)$ & ) 1972 (1950-1998) & ) 1970 (1958-1985 \\
\hline Median years at Y-12 (range) & $25(<1-47)$ & $24(<1-47)$ & $19(3-40) \neq$ & $22(2-31)$ \\
\hline Median number of job titles (range) & $2(1-7)$ & $2(1-5)$ & $3(1-5)$ & $2.5(1-5)$ \\
\hline $\begin{array}{l}\text { Median number of beryllium exposure tasks } \\
\text { (range) }\end{array}$ & $2(0-8)$ & $1(0-4) \ddagger$ & $2(1-5) \S$ & $2(0-5)$ \\
\hline
\end{tabular}


Table 2 Exposure estimates by case status for Y-12 participants

\begin{tabular}{|c|c|c|c|c|}
\hline Exposure metric & Control & BeS & CBD & $\mathrm{BeS} / \mathrm{CBD}$ \\
\hline All participants, $\mathrm{n}$ & 127 & 35 & 19 & 54 \\
\hline Year of first beryllium exposure & $1970(1970)$ & $1973(1970)$ & $1973(1969)$ & $1973(1970)$ \\
\hline Years with direct beryllium exposure* & $3.2(1.3)$ & $2.1(0.48)$ & $3.7(2.3) \S$ & $2.6(1.4)$ \\
\hline Assigned cumulative exposure, $\mu \mathrm{g} / \mathrm{m}^{3}$-years & $3.91(0.98)$ & $3.44(0.26) \Phi$ & $8.79(2.64) \rrbracket \S$ & $5.33(0.89)$ \\
\hline Assigned lifetime-weighted average exposure, $\mu \mathrm{g} / \mathrm{m}^{3}$ & $0.13(0.03)$ & $0.12(0.02)$ & $0.32(0.11) \neq \S$ & $0.19(0.04)$ \\
\hline Highest task exposure, $\dagger \mu \mathrm{g} / \mathrm{m}^{3}$ & $1.81(1.00)$ & $1.16(0.26) \neq$ & $3.75(1.19) \neq \S$ & $2.07(0.63)$ \\
\hline Participants never working at K-25, n & 80 & 14 & 10 & 24 \\
\hline Year of first beryllium exposure & 1971 (1969) & $1970(1970)$ & $1970(1970)$ & $1970(1970)$ \\
\hline Years with direct beryllium exposure ${ }^{*}$ & $3.5(1.2)$ & $3.8(2.4)$ & $5.7(4.2) \ddagger$ & $4.6(3.4) \Phi$ \\
\hline Assigned cumulative exposure, $\mu \mathrm{g} / \mathrm{m}^{3}$-years & $5.24(1.02)$ & $3.88(2.43)$ & $15.31(3.86) \neq$ & $8.64(3.08) 9$ \\
\hline Assigned lifetime-weighted average exposure, $\mu \mathrm{g} / \mathrm{m}^{3}$ & $0.17(0.03)$ & $0.15(0.10)$ & $0.54(0.13) \ddagger$ & $0.31(0.12) \neq$ \\
\hline Highest task exposure, $\dagger \mu \mathrm{g} / \mathrm{m}^{3}$ & $2.05(1.00)$ & $1.08(0.38)$ & $3.27(1.78)$ & $1.99(1.00)$ \\
\hline
\end{tabular}

Values are mean (median).

*Years $\times \%$ time.

†Maximum assigned beryllium exposure for any work task regardless of length of exposure.

$\neq p<0.05$ versus controls (Wilcoxon rank sum).

$\S \mathrm{p}<0.05$ versus BeS (Wilcoxon rank sum).

$\uparrow 0.05<\mathrm{p}<0.10$ versus controls (Wilcoxon rank sum).

$\mathrm{BeS}$, beryllium sensitisation; $\mathrm{CBD}$, chronic beryllium disease.

with an underlying genetic susceptibility factor is being considered, and has been found in other studies. When coding HLA-DPB1 alleles as DP $\beta E 69$ positive or negative, CBD cases $(p=0.09)$, BeS cases $(p=0.13)$ and controls $(p=0.61)$ were all in Hardy-Weinberg equilibrium. A table showing the HLA-DPB1 allele frequencies by disease status is included in the online data supplement for additional details. DP $\beta$ E69 carrier frequency was significantly higher for both $\mathrm{BeS}$ cases $(82 \%, \mathrm{p}<0.001)$ and $\mathrm{CBD}$ cases $(89 \%, p<0.001)$ as compared to controls $(36 \%)$. In fact, only eight individuals with BeS or CBD were not carriers of DP $\beta E 69$. DP $\beta E 69$ carrier frequency was not significantly different between $\mathrm{CBD}$ cases and BeS cases even after excluding BeS cases who had not undergone a full clinical evaluation. In terms of DP $\beta E 69$ zygosity, homozygotes comprised $20 \%$ ( $n=7$, $p=0.007$ vs controls) of BeS cases and $21 \%(n=4, p=0.030$ vs controls) of $\mathrm{CBD}$ cases compared to $3 \%(n=4)$ of controls. Because of similar genetic results between $\mathrm{CBD}$ and $\mathrm{BeS}$ cases, small numbers of cases of either $\mathrm{CBD}$ or $\mathrm{BeS}$ alone compared to controls, and potential misclassification of some of the BeS cases, we combined the $\mathrm{CBD}$ and $\mathrm{BeS}$ cases for additional analyses.

\section{Gene-environment interaction}

Genetic and exposure variables were fit to logistic regression models to assess the combined effect of genetics and exposure on the odds of developing BeS/CBD. The most predictive model (table 3) included DPßE69 status, number of years worked at Y-12, ever having worked at K-25, assigned lifetime-weighted average exposure as a binary covariate (exposure above or below $0.1 \mu \mathrm{g} / \mathrm{m}^{3}$ ) and an interaction between the exposure variable and ever working at K-25. Of note, $77 \%(n=44)$ of BeS/CBD cases either had assigned lifetime-weighted average exposures exceeding $0.1 \mu \mathrm{g} / \mathrm{m}^{3}$ or had worked at K-25 compared to $54 \%$ $(n=69)$ of controls $(p<0.001)$. Based on this model, an increased odds of BeS/CBD was shown for DP $\beta E 69$ carriers (OR 11.9, 95\% CI 4.91 to 28.7), while each additional year of work time was slightly protective (OR $0.96,95 \%$ CI 0.92 to 1.00). Exposure effects depended on work at K-25 with ever working at K-25 increasing the odds for the high exposure group (OR 16.5, 95\% CI 2.77 to 97.8) as compared to never working at K-25 (OR 4.79, $95 \%$ CI 1.61 to 14.2 ). The odds for those never working at K-25 with high exposure appear to be similar to the odds among the low exposure group for those who did work at K-25 (OR 3.43, 95\% CI 1.30 to 9.07 ).

As we were unable to accurately reconstruct the K-25 exposures, an additional multivariate model was fit excluding those who ever worked at K-25 (table 4). In this model, the odds of $\mathrm{BeS} / \mathrm{CBD}$ for DP $\beta \mathrm{E} 69$ carriers was increased approximately sixfold (OR 6.06, 95\% CI 1.96 to 18.7) and the odds for those with assigned lifetime-weighted average exposure over $0.1 \mu \mathrm{g} / \mathrm{m}^{3}$ was increased about fourfold (OR 3.98, 95\% CI 1.43 to 11.0 ). The odds for those individuals with both DP $\beta E 69$ and higher exposure were further increased based on the logistic model (OR 24.1, 95\% CI 4.77 to 122). The interaction term between exposure and DPBE69 did not significantly contribute to any of the models. Details of a number of inclusion and exclusion modifications to the above model are discussed further in the online data supplement.

\section{DISCUSSION}

In this case-control study of beryllium-exposed workers in the nuclear weapons industry, we confirmed increased susceptibility to $\mathrm{BeS} / \mathrm{CBD}$ among carriers of the DP $\beta E 69$ genotype with

Table 3 Logistic regression model for odds of BeS/CBD (including all who worked at K-25)

\begin{tabular}{|c|c|c|}
\hline Independent effects & $\begin{array}{l}\text { Estimated } \\
\text { coefficients }\end{array}$ & OR (95\% Cl) \\
\hline Intercept & -2.45 & \\
\hline $\mathrm{DP} \beta \mathrm{E} 69+$ & 2.47 & 11.9 (4.91 to 28.7$)$ \\
\hline Per year increase in work years at $\mathrm{Y}-12$ & -0.04 & $0.96(0.92$ to 1.00$)$ \\
\hline $\begin{array}{l}\text { Assigned lifetime-weighted average } \\
\text { (LTWA) exposure }{ }^{*}>0.1 \mu \mathrm{g} / \mathrm{m}^{3}\end{array}$ & 1.56 & See below \\
\hline Ever having worked at $\mathrm{K}-25$ & 1.23 & See below \\
\hline $\begin{array}{l}\text { Assigned LTWA exposure }{ }^{*} \times \text { Ever having } \\
\text { worked at K-25 }\end{array}$ & -1.58 & See below \\
\hline \multicolumn{3}{|l|}{ Interaction effects } \\
\hline \multicolumn{3}{|l|}{ Ever having worked at $\mathrm{K}-25$} \\
\hline Assigned LTWA exposure $>0.1 \mu \mathrm{g} / \mathrm{m}^{3}$ & 2.80 & 16.5 (2.77 to 97.8$)$ \\
\hline Assigned LTWA exposure $\leq 0.1 \mu \mathrm{g} / \mathrm{m}^{3}$ & 1.23 & $3.43(1.30$ to 9.07$)$ \\
\hline \multicolumn{3}{|l|}{ Never having worked at K-25 } \\
\hline $\begin{array}{l}\text { Assigned LTWA exposure }>0.1 \mu \mathrm{g} / \mathrm{m}^{3} \\
\text { Assigned LTWA exposure } \leq 0.1 \mu \mathrm{g} / \mathrm{m}^{3}\end{array}$ & 1.57 & $\begin{array}{l}4.79 \text { (1.61 to } 14.2 \text { ) } \\
\text { (Reference group) }\end{array}$ \\
\hline
\end{tabular}

*Assigned lifetime-weighted average exposure based on interview and $\mathrm{IH}$ task assessment. $\mathrm{BeS}$, beryllium sensitisation; CBD, chronic beryllium disease; $I H$, industrial hygiene. 
Table 4 Logistic regression model for odds of BeS/CBD (excluding all who worked at K-25)

\begin{tabular}{lcl}
\hline Independent effects & $\begin{array}{l}\text { Estimated } \\
\text { coefficients }\end{array}$ & OR (95\% CI) \\
\hline Intercept & -2.88 & \\
DP $\beta E 69+$ & 1.80 & 6.06 (1.96 to 18.7) \\
Assigned lifetime weighted average & 1.38 & 3.98 (1.43 to 11.0) \\
(LTWA) exposure* $>0.1 \mu \mathrm{g} / \mathrm{m}^{3}$ & & \\
\hline
\end{tabular}

${ }^{*}$ Assigned lifetime-weighted average exposure based on interview and $\mathrm{IH}$ task assessment. $\mathrm{BeS}$, beryllium sensitisation; $\mathrm{CBD}$, chronic beryllium disease; $\mathrm{IH}$, industrial hygiene.

similar genotype frequencies as have been reported in previous cross-sectional studies. ${ }^{14-21}$ Similar DP $\beta E 69$ genotype frequencies were noted for cases of $\mathrm{CBD}$ and $\mathrm{BeS}$, supporting the notion that DP $\beta E 69$ status is important for antigen presentation and as a supratypic marker is not predictive of progression from BeS to CBD. ${ }^{24-26}$ We also found evidence of increased prevalence of $\mathrm{BeS} / \mathrm{CBD}$ at assigned lifetime-weighted average exposures exceeding $0.1 \mu \mathrm{g} / \mathrm{m}^{3}$ and confirmed that BeS cases occurred among workers with very low estimated exposures, as demonstrated by previous reports. ${ }^{4} 5$ Most importantly, we demonstrated that higher exposure and genetic susceptibility via DP $\beta E 69$ each individually conferred similar levels of increased risk of BeS/CBD among workers at a beryllium-using facility.

The study confirms the individual contributions of exposure and genetics (DPBE69 status) to the development of BeS/CBD. In our current study, excluding participants who ever worked at K-25, DP $\beta E 69$ conferred about a sixfold increased odds and high exposure about a fourfold increased odds, suggesting that exposure and DP $\beta E 69$ each contribute to risk of BeS and CBD and at a similar magnitude individually. There is only one previous study of exposure and genetics in CBD demonstrating that beryllium exposure surrogates (work as a machinist) and DPBE69 contributed individually to CBD. ${ }^{15}$ Although the point estimates identified by the previous study were slightly higher, showing a 12-fold increased odds for DPBE69 carriers and a 10-fold increased odds from working as a beryllium machinist, the confidence limits overlap with those in our current study. In both studies, the magnitude of the increased odds was very similar for either risk factor, suggesting similar increased odds when comparing high exposure in the absence of the genetic susceptibility factor (DP $\beta$ E69) and low exposure for carriers of the DP $\beta E 69$ susceptibility factor. Due to small numbers of DP $\beta E 69$ homozygotes in our study population, we were unable to effectively demonstrate differences in exposure effects as compared to DP $\beta E 69$ heterozygotes. As with the previous study, the interaction between exposure and genetics was not statistically significant, however, this finding should not be interpreted as a lack of interaction since the power to detect an interaction term with a minimum OR of 6 was $<20 \%$ given our sample size and population characteristics. ${ }^{27}$ The results from our study with an OR of 24 for those individuals with both DP $\beta E 69$ and higher exposure suggest individual contributions of exposure and genetics to BeS/CBD risk rather than a gene-environment interaction. Our results have important implications for worker protection in that high exposure confers increased risk even in the absence of the DP $\beta E 69$ genetic susceptibility. Furthermore, with high exposure and genetic susceptibility the risk is much higher, supporting efforts and public policy to reduce exposure to beryllium in the workplace for those who are more susceptible.

This is the first published report of increased odds of $\mathrm{CBD} / \mathrm{BeS}$ at higher average beryllium exposures in this Department of Energy facility. We report increasing risk of BeS/CBD with life- time-weighted average assigned exposures exceeding $0.1 \mu \mathrm{g} / \mathrm{m}^{3}$ that became more pronounced after adjusting for the DP $\beta E 69$ genetic factor. As noted above, multivariate modelling showed a fourfold increased odds of BeS/CBD for those exposed to over $0.1 \mu \mathrm{g} / \mathrm{m}^{3}$. This increased risk is consistent with reports of exposure-response relationships in a previous case-control study $^{28}$ and two cross-sectional studies. ${ }^{5} 29$ However, not all previous studies have found an exposure-response relationship in $\mathrm{BeS}$ or CBD. It is likely that inclusion of genetic susceptibility, an important risk factor for both BeS and $\mathrm{CBD}$, helped clarify the exposure-disease relationship. The increasing occurrence of $\mathrm{BeS}$ and $\mathrm{CBD}$ at higher average exposures underscores the need for serial medical surveillance to identify workers with BeS and $\mathrm{CBD}$ early and to reduce exposure to beryllium to reduce the risk of $\mathrm{BeS}$ and $\mathrm{CBD}$.

Confirming previous reports, ${ }^{45}$ we identified BeS cases at very low apparent exposures. Of interest is the finding that nearly one-third of BeS cases reported only indirect exposure to beryllium and nearly $20 \%$ reported their highest exposure was working only in the same building as a beryllium operation (see online data supplement). In contrast to BeS cases and in contrast to reports from other nuclear weapons facilities where CBD was identified in individuals with very low apparent exposure such as a secretary and a security guard, ${ }^{5} 3031$ all of the CBD cases reported direct exposure to beryllium operations, such as during machining, metal forming and beryllium machine maintenance. While work as a machinist, a surrogate for higher exposure, has been associated with risk of CBD in previous cross-sectional studies, ${ }^{4} 59$ we found only a trend towards increased risk of CBD for beryllium machinists (see online data supplement). Otherwise, there were very few significant differences between cases of either BeS or CBD and controls in terms of either job classification or task-related exposure at Y-12. The multivariate analyses collapsing $\mathrm{CBD}$ and $\mathrm{BeS}$ combined with the $15 \mathrm{BeS}$ cases without a full clinical evaluation could have masked important differences in beryllium exposure for the two outcomes. As documented by other researchers, chemical form ${ }^{6}$ of beryllium and particle size $e^{7-10}$ are likely important for both $\mathrm{BeS}$ and $\mathrm{CBD}$. It is also possible that $\mathrm{BeS}$ is related to different exposure metrics such as dermal exposure ${ }^{11-13}$ and short-term peak exposures ${ }^{32}$ as compared to CBD, which may be more highly related to cumulative or average beryllium exposure.

We identified important confounders of the exposure-disease relationship among workers at Y-12. Ever working at the K-25 facility increased the risk of BeS/CBD among Y-12 workers in this study. Based on evaluation of specific operations at K-25, work as a barrier operator was associated with a significantly higher risk of CBD and work in production support operations was associated with a higher risk of BeS. Limited beryllium use has been documented at K-25, including short-term contract machining operations for Y-12. However, the use of beryllium at $\mathrm{K}-25$ was not considered to be widespread. The magnitude of the increased risk suggested by multivariate analyses suggests that a significant beryllium exposure source at K-25 was not considered in assigning exposures. In addition, assuming there was an exposure source, workers had very little knowledge regarding beryllium use at K-25, with only 14 of the 77 participants who had worked at K-25 reporting beryllium exposure. This lack of knowledge regarding beryllium exposure at K-25 is not surprising due to the nature of the classified work at the facility.

Counter to our expectations, the second confounding factor identified was the apparent protective effect of increasing work years on the risk of BeS/CBD. While there have been 
reports of $\mathrm{BeS}$ occurring within a short period of time after first exposure $^{9} 3334$ and others have reported similar protective effects in multivariate models, ${ }^{35}$ this study would likely not detect early BeS as most of the cases were first screened many years after first exposure to beryllium. Of the BeS/CBD cases in our study, $42 \%$ were diagnosed as current workers with their exposure years (ie, assigned lifetime-weighted average exposure denominator) truncated by on average 4.7 years. None of these workers left employment with Y-12 as a result of their diagnosis. As the confounder was actual years worked at Y-12 rather than exposure years, it is unlikely to be related to truncating exposures for cases. However, as our study did not include frequency matching for the number of years worked, it is possible that this apparent protective effect is a result of the increased participation by long-term workers in the control group and not a true protective effect. It is also possible this confounding was due to a healthy worker effect with symptomatic workers leaving employment at Y-12 early in their career with a later diagnosis of $\mathrm{BeS}$ or CBD.

Exposure misclassification could have impacted our results. Assigned cumulative exposures may have been overestimated for $\mathrm{BeS} / \mathrm{CBD}$ cases as exposures accrued until the date of BeS or $\mathrm{CBD}$ diagnosis, which was likely much later than the date of disease development. Differential recall bias due to interviewing workers after BeS/CBD diagnosis could have resulted in differential exposure misclassification. Although other researchers have found few differences in the validity and reliability of exposures reported by cases and controls, ${ }^{36-39}$ it is possible that cases had spent more time analysing their work to identify a possible cause of their diagnosis and were more likely to report beryllium exposure as compared to controls. We tried to reduce the likelihood of recall bias by asking study participants to describe their exposures on a well-defined scale and relate their exposures to specific tasks performed rather than to assess their intensity of exposure on an arbitrary high, medium or low scale. Exposure misclassification may have occurred due to unequal awareness of processes with beryllium exposure among study participants. This misclassification was likely differential with respect to comparing participants with direct exposure to those with only indirect exposure. However, it is unlikely that unequal awareness resulted in differential exposure misclassification in comparing cases and controls. Assigning exposures to beryllium tasks using industrial hygiene measurements from similar processes at other facilities rather than facility-specific measurements likely resulted in misclassification on an absolute $\mu \mathrm{g} / \mathrm{m}^{3}$ scale, but less misclassification on a relative scale for comparing study participants. In assigning beryllium exposure estimates to tasks rather than individuals, the misclassification on both the absolute and relative scale should have been nondifferential. Lack of knowledge regarding exposures at other Oak Ridge facilities (K-25 and X-10) may have also resulted in misclassification of exposures. We attempted to control for this misclassification by including variables for work at these facilities in our multivariate models. In spite of these potential misclassifications, we did find exposure-response relationships for $\mathrm{BeS} / \mathrm{CBD}$ in our multivariate models and with the limited industrial hygiene exposure data currently available from the Y-12 facility, we could not have reconstructed exposure estimates on an absolute $\mu \mathrm{g} / \mathrm{m}^{3}$ scale with less misclassification. It is possible, although unlikely, that genotyping misclassification might have impacted our results. With the use of PCR-SSP genotyping methods, it is possible that there was misclassification of genotypes. This is less likely to have caused misinterpretation of the results as (1) we have confirmed PCR-SSP results with methods used in a transplantation laboratory (data not shown) and (2) the analysis was conducted based on DP $\beta E 69$ presence and not on alleles or amino acid sequence.

\section{CONCLUSION}

This study evaluates the contribution of DP $\beta E 69$, a well known marker of susceptibility for BeS/CBD, along with beryllium exposure to the risk of beryllium-related health effects. In this study, DP $\beta E 69$ carriage and high exposure each contribute individually and with a similar risk magnitude for BeS/CBD. Furthermore, together high exposure and genetic susceptibility appear to confer the highest risk for BeS/CBD. Confirming previous reports, there appears to be a sub-population of individuals at high risk for BeS even at very low apparent exposures. Future studies will be needed to address interactions with other genes in the HLA region and the effects of DP $\beta E 69$ and exposure on the development of $\mathrm{CBD}$ and $\mathrm{BeS}$ independently as different gene-exposure-response relationships may be apparent in larger populations. This study emphasises the need to include known genetic susceptibility factors in the analysis of $\mathrm{BeS} / \mathrm{CBD}$ to help clarify important exposures for sensitive subpopulations. It also supports additional studies with contemporary exposure measurements in $\mu \mathrm{g} / \mathrm{m}^{3}$ to define appropriate exposure limits for this susceptible population. From a practical standpoint, this study supports the need for exposure reduction in the workplace aimed at the more susceptible population, carriers of DP $\beta E 69$

Acknowledgements The authors wish to thank the $\mathrm{Y}-12$ current and former workers who participated in this research; Gina Mondello and Holly Sackett who facilitated the study process; May Gillespie, Starza Duskin, Alexas Jonth and Jill Elliot for their efforts genotyping the study participants; Dr Otis Cosby, Dr David Wehrley, Debbie Hurst, Tom Ford, Jim Jenkins, Scott Anderson and Richard Baylor for their assistance at the Y-12 facility; Tim Alcorn, Sandra King and Melanie Dake for their assistance with exposure interviews; and Dr Stephen Reynolds, Del Sandfort, Dr Tom Keefe and Dr Tracy Nelson for their review of this manuscript.

Funding This study was supported by grant P01 ES011810 from NIEHS/NIH and 1 UL1 RR025780 from NCRR/NIH.

Competing interests MVV, JWM, MMM, LJS, MS and LAM are employed by National Jewish Health, a non-profit medical institution that offers the beryllium lymphocyte proliferation test on a commercial basis and provides medical surveillance and consultation to beryllium industries. DLC, WGT and SMW are employed by Oak Ridge Associated Universities which provide medical surveillance including the beryllium lymphocyte proliferation test to facilities using beryllium containing materials. LSN is the CEO of Axion Health, a company also providing medical surveillance services to beryllium using facilities.

Ethics approval This study was conducted with the approval of the National Jewish Health IRB and US Department of Energy Central IRB.

Provenance and peer review Not commissioned; externally peer reviewed.

\section{REFERENCES}

1. Rosenman K, Hertzberg V, Rice C, et al. Chronic beryllium disease and sensitization at a beryllium processing facility. Environ Health Perspect 2005;113:1366-72

2. Kreiss K, Newman LS, Mroz MM, et al. Screening blood test identifies subclinical beryllium disease. J Occup Med 1989;31:603-8.

3. Stanton ML, Henneberger PK, Kent MS, et al. Sensitization and chronic beryllium disease among workers in copper-beryllium distribution centers. J Occup Environ Med 2006;48:204-11.

4. Kreiss K, Mroz MM, Newman LS, et al. Machining risk of beryllium disease and sensitization with median exposures below 2 micrograms/m3. Am J Ind Med 1996;30:16-25.

5. Kreiss K, Mroz MM, Zhen B, et al. Epidemiology of beryllium sensitization and disease in nuclear workers. Am Rev Respir Dis 1993;148:985-91.

6. Stefaniak AB, Hoover MD, Day GA, et al. Characterization of physicochemical properties of beryllium aerosols associated with prevalence of chronic beryllium disease. J Environ Monit 2004;6:523-32.

7. Kent MS, Robins TG, Madl AK. Is total mass or mass of alveolar-deposited airborne particles of beryllium a better predictor of the prevalence of disease? A preliminary study of a beryllium processing facility. Appl Occup Environ Hyg 2001;16:539-58. 
8. Martyny JW, Hoover MD, Mroz MM, et al. Aerosols generated during beryllium machining. J Occup Environ Med 2000;42:8-18.

9. Kelleher PC, Martyny JW, Mroz MM, et al. Beryllium particulate exposure and disease relations in a beryllium machining plant. J Occup Environ Med 2001;43:238-49.

10. Virji MA, Stefaniak AB, Day GA, et al. Characteristics of beryllium exposure to small particles at a beryllium production facility. Ann Occup Hyg 2011;55:70-85.

11. Tinkle SS, Antonini JM, Rich BA, et al. Skin as a route of exposure and sensitization in chronic beryllium disease. Environ Health Perspect 2003;111:1202-8.

12. Day GA, Stefaniak $A B$, Weston $A$, et al. Beryllium exposure: dermal and immunological considerations. Int Arch Occup Environ Health 2006;79:161-4.

13. Stefaniak AB, Virji MA, Day GA. Release of beryllium from berylliumcontaining materials in artificial skin surface film liquids. Ann Occup Hyg 2011;55:57-69.

14. Richeldi L, Sorrentino R, Saltini C. HLA-DPB1 glutamate 69: a genetic marker of beryllium disease. Science 1993;262:242-4.

15. Richeldi L, Kreiss K, Mroz MM, et al. Interaction of genetic and exposure factors in the prevalence of berylliosis. Am J Ind Med 1997;32:337-40.

16. Wang Z, White PS, Petrovic M, et al. Differential susceptibilities to chronic beryllium disease contributed by different Glu69 HLA-DPB1 and -DPA1 alleles. J Immunol 1999;163:1647-53.

17. Saltini C, Richeldi L, Losi M, et al. Major histocompatibility locus genetic markers of beryllium sensitization and disease. Eur Respir J 2001:18:677-84.

18. Rossman MD, Stubbs J, Lee CW, et al. Human leukocyte antigen Class II amino acid epitopes: susceptibility and progression markers for beryllium hypersensitivity. Am J Respir Crit Care Med 2002;165:788-94.

19. Maier LA, McGrath DS, Sato H, et al. Influence of MHC CLASS II in susceptibility to beryllium sensitization and chronic beryllium disease. J Immunol 2003:171:6910-18.

20. McCanlies EC, Ensey JS, Schuler CR, et al. The association between HLA-DPB1Glu69 and chronic beryllium disease and beryllium sensitization. Am J Ind Med 2004;46:95-103.

21. Wang Z, Farris GM, Newman LS, et al. Beryllium sensitivity is linked to HLA-DP genotype. Toxicology 2001;165:27-38.

22. Rosenman KD, Rossman M, Hertzberg V, et al. HLA class II DPB1 and DRB1 polymorphisms associated with genetic susceptibility to beryllium toxicity. Occup Environ Med 2011;68:487-93.

23. Welsh K, Bunce M. Molecular typing for the MHC with PCR-SSP. Rev Immunogenet 1999;1:157-76.

24. Snyder JA, Demchuk E, McCanlies EC, et al. Impact of negatively charged patches on the surface of MHC class II antigen-presenting proteins on risk of chronic beryllium disease. J R Soc Interface 2008;5:749-58.
25. Snyder JA, Weston A, Tinkle SS, et al. Electrostatic potential on human leukocyte antigen: implications for putative mechanism of chronic beryllium disease. Environ Health Perspect 2003;111:1827-34.

26. Fontenot AP, Torres M, Marshall WH, et al. Beryllium presentation to CD4+ T cells underlies disease-susceptibility HLA-DP alleles in chronic beryllium disease. Proc Nat Acad Sci U S A 2000:97:12717-22.

27. Demidenko E. Sample size and optimal design for logistic regression with binary interaction. Stat Med 2008;27:36-46

28. Viet SM, Torma-Krajewski J, Rogers J. Chronic beryllium disease and beryllium sensitization at Rocky Flats: a case-control study. Am Ind Hyg Assoc J 2000;61:244-54.

29. Kreiss K, Wasserman S, Mroz MM, et al. Beryllium disease screening in the ceramics industry. Blood lymphocyte test performance and exposure-disease relations. J Occup Med 1993;35:267-74.

30. Stange AW, Furman FJ, Hilmas DE. Rocky flats beryllium health surveillance. Environ Health Perspect 1996;104S:981-6.

31. Welch L, Ringen K, Bingham E, et al. Screening for beryllium disease among construction trade workers at Department of Energy nuclear sites. Am J Ind Med 2004:46:207-18

32. Schuler CR, Kent MS, Deubner DC, et al. Process-related risk of beryllium sensitization and disease in a copper-beryllium alloy facility. Am J Ind Med 2005; 47:195-205.

33. Cummings KJ, Deubner DC, Day GA, et al. Enhanced preventive programme at a beryllium oxide ceramics facility reduces beryllium sensitisation among new workers. Occup Environ Med 2007;64:134-40.

34. Henneberger PK, Cumro D, Deubner DD, et al. Beryllium sensitization and disease among long-term and short-term workers in a beryllium ceramics plant. Int Arch Occup Environ Health 2001:74:167-76.

35. Kreiss K, Mroz MM, Zhen B, et al. Risks of beryllium disease related to work processes at a metal, alloy, and oxide production plant. Occup Environ Med 1997:54:605-12

36. Joffe M. Validity of exposure data derived from a structured questionnaire. Am J Epidemiol 1992; 135:564-70.

37. Blair A, Zahm SH. Patterns of pesticide use among farmers: implications for epidemiologic research. Epidemiology 1993:4:55-62.

38. Fritschi L, Siemiatycki J, Richardson L. Self-assessed versus expert-assessed occupational exposures. Am J Epidemiol 1996:144:521-7.

39. Nordstrom DL, Vierkant RA, Layde PM, et al. Comparison of self-reported and expert-observed physical activities at work in a general population. Am J Ind Med 1998;34:29-35. 